Acta Crystallographica Section B

Structural

Science

ISSN 0108-7681

Structures of Fluoroarsenates $\mathrm{KAsF}_{6 n}(\mathrm{OH})_{n}, \boldsymbol{n}=\mathbf{0 , 1}, 2$ : Application of the Heavy-Atom Method for Modulated Structures

J. Peterková, M. Dusek, V. Petrícek and J. Loub

This electronic document was scanned from an archival copy of material deposited to accompany a paper published in an IUCr journal. In many cases the only accessible copy was a microfilm of a poor-quality original. 


\section{Data for deposition:}

1) FoFc table for $\mathrm{KAsF}_{6}$

2) FoFc table for $\mathrm{KAsF}_{5}(\mathrm{OH})$

3) $\mathrm{FoFc}_{\mathrm{fable}}$ for $\mathrm{KAsF}_{4}(\mathrm{OH})_{2}$

4) Final values for temperature parameters. The temperature factor is defined as $\exp \left[-2 \pi^{2}\left(U_{11} h^{2} a^{* 2}+U_{22} k^{2} b^{* 2}+U_{33} l^{2} c^{* 2}+U_{12} h k^{2} a^{*} b^{*}+U_{13} h l^{2} a^{*} c^{*}+U_{23} k l^{2} b^{*} c^{*}\right)\right]$

4) $\mathrm{KAsF}_{6}$ : Final values for temperature parameters

$\begin{array}{lllllll}\text { K } & 0.0349(2) & 0.0349(2) & 0.0255(3) & 0.0174(1) & 0.0000(0) & 0.0000(0) \\ \text { As } & 0.0206(1) & 0.0206(1) & 0.0196(2) & 0.01029(6) & 0.0000(0) & 0.0000(0) \\ \text { F } & 0.0406(5) & 0.0316(5) & 0.0413(5) & 0.0147(4) & -0.0090(4) & -0.0145(4)\end{array}$

$\mathrm{KAsF}_{5}(\mathrm{OH})$ : Final values for temperature parameters

$\begin{array}{lllllll}\text { Atom } & \mathrm{U} 11 & \mathrm{U} 22 & \mathrm{U} 33 & \mathrm{U} 12 & \mathrm{U} 13 & \mathrm{U} 23 \\ \mathrm{Ka} & 0.0369(7) & 0.0403(8) & 0.0412(8) & 0.0(0) & 0.0075(6) & 0.0(0) \\ \text { Kb } & 0.0313(5) & 0.0366(5) & 0.0303(5) & -0.0034(4) & -0.0013(4) & 0.0021(4) \\ \text { Kc } & 0.0317(5) & 0.0310(5) & 0.0323(5) & 0.0028(4) & 0.0012(4) & 0.0012(4) \\ \text { Kd } & 0.0314(6) & 0.0288(6) & 0.0312(7) & 0.0(0) & 0.0013(5) & 0.0(0) \\ \text { As1a } & 0.0186(2) & 0.0182(2) & 0.0261(2) & -0.0003(1) & -0.0005(1) & -0.0004(1) \\ \text { F1a } & 0.025(1) & 0.041(2) & 0.076(3) & -0.013(1) & -0.001(1) & 0.003(1) \\ \text { O2a } & 0.020(1) & 0.029(2) & 0.059(2) & -0.002(1) & 0.000(1) & 0.001(2) \\ & & & & & \\ \text { F3a } & 0.040(2) & 0.044(2) & 0.054(2) & 0.002(1) & 0.012(1) & -0.024(1) \\ \text { F4a } & 0.048(2) & 0.048(2) & 0.055(2) & 0.002(2) & -0.003(2) & 0.028(2) \\ \text { F5a } & 0.036(2) & 0.044(2) & 0.049(2) & 0.001(1) & -0.010(1) & 0.019(1) \\ \text { F6a } & 0.053(2) & 0.047(2) & 0.053(2) & 0.007(2) & 0.000(2) & -0.027(2) \\ \text { As2b } & 0.0266(2) & 0.0194(2) & 0.0247(2) & -0.0015(1) & 0.0002(1) & -0.0012(1) \\ \text { F1b } & 0.101(3) & 0.021(1) & 0.052(2) & -0.010(2) & 0.016(2) & -0.001(1) \\ \text { O2b } & 0.053(2) & 0.021(2) & 0.065(3) & -0.001(2) & 0.009(2) & 0.003(1) \\ & & & & & & -0.001(3) \\ \text { F4b } & 0.071(3) & 0.071(3) & 0.118(4) & 0.015(2) & -0.058(3) & -0.005(2) \\ \text { F5b } & 0.092(3) & 0.048(2) & 0.053(2) & 0.003(2) & 0.033(2) & -0.013(2) \\ \text { F6b } & 0.040(2) & 0.079(3) & 0.096(3) & 0.000(2) & -0.030(2) & -0.003(2) \\ \text { F3b } & 0.125(4) & 0.046(2) & 0.043(2) & -0.005(2) & 0.037(2) & 0.0002(1) \\ \text { As1c } & 0.0183(2) & 0.0215(2) & 0.0273(2) & -0.0013(1) & 0.0012(1) & -0.011(2) \\ \text { F1c } & 0.024(1) & 0.049(2) & 0.075(2) & -0.014(1) & 0.011(1) & 0.002(2) \\ \text { O2c } & 0.019(1) & 0.032(2) & 0.064(2) & 0.000(1) & 0.000(1) & -0.044(2) \\ \text { F3c } & 0.036(2) & 0.058(2) & 0.094(3) & -0.004(2) & 0.011(2) & 0.070(3) \\ \text { F4c } & 0.054(2) & 0.096(3) & 0.098(3) & 0.020(2) & 0.009(2) & 0.060(3) \\ \text { F5c } & 0.039(2) & 0.129(4) & 0.069(3) & -0.001(2) & -0.006(2) & -0.077(3) \\ \text { F6ax } & 0.050(2) & 0.087(3) & 0.129(4) & -0.018(2) & 0.033(2) & \end{array}$

